\title{
BLASTOCYST SIZE IN DUTCH-BELTED AND NEW ZEALAND RABBITS*
}

\author{
G. E. KODITUWAKKU† AND E. S. E. HAFEZ \\ Reproduction Laboratory, Department of Animal Sciences, \\ Washington State University, Pullman, Washington, U.S.A.
}

(Received 13th November 1968, revised 7th February 1969)

In the rabbit, blastocyst size varies greatly from one doe to another, and is not apparently related to such factors as the weight of the dam and sire or the age of the dam (Beatty, 1958), and the parity of the female (Hafez \& Rajakoski, 1964). On the other hand, lactation and stress cause a reduction in the size of the blastocyst and the diameter of the embryonic disc (Hafez \& Ishibashi, 1965), and blastocyst diameter is directly related to the racial size of the parents (Castle \& Gregory, 1929). The present investigation was undertaken to evaluate the variation in blastocyst size between two breeds of rabbits of different body size.

Twenty-three New Zealand White (adult body weight $3 \cdot 2$ to $4 \cdot 2 \mathrm{~kg}$ ) and thirtythree Dutch-Belted (adult body weight 1.6 to $2.3 \mathrm{~kg}$ ) oestrous rabbits were mated with two fertile bucks of their respective breeds and injected with 20 i.u. of HGG (Follutein, Squibb). They were killed 144, 152 and $160 \mathrm{hr}$ post coitum (p.c.), and their uteri flushed with physiological saline for the recovery of blastocysts. The outer and inner zonal diameter and the embryonic disc of the blastocysts were measured in a constant depth of fluid, as described by Hafez \& Rajakoski (1964). Of the 230 blastocysts recovered from the New Zealand does, twenty had degenerated and seven ruptured during the flushing process. Of the 168 blastocysts flushed from the Dutch-Belted breed, forty were degenerate and six ruptured while flushing. The 160-hr blastocysts of both breeds were extremely fragile and the ruptured blastocysts from this age group were not included in this study.

Viable blastocysts were recovered from twenty of the twenty-three New Zealand White does, whilst in the Dutch-Belted breed, only twenty-four of the thirty-three does provided viable blastocysts. The percentage of does with viable blastocysts, the number of blastocysts per doe, and the number of corpora lutea per doe were higher in the New Zealand than in the Dutch-Belted breed (Table 1). Dutch-Belted does had more degenerate blastocysts. The data on blastocyst size are summarized in Table 2.

There were no significant differences in the outer- and inner-zonal diameters and the diameter of the embryonic disc between the two breeds. However, the

\footnotetext{
* Scientific Paper 3188, Washington State University College of Agriculture Research Center, Project 1698 .

$\dagger$ Fullbright-Hays Postdoctoral Research Fellow, U.S. Department of State. Present address: Faculty of Veterinary Medicine, University of Ceylon, Peradeniya, Ceylon.
} 
diameter of individual blastocysts varied widely, even within the same litter, and the range of this variation seemed to vary with the breed. There was a

TABLE 1

RECOVERY OF BLASTOCYSTS FROM DUTCH-BELTED AND NEW ZEALAND RABBITS 144 TO $160 \mathrm{HR}$ p.c.

\begin{tabular}{|c|c|c|}
\hline & Dutch-Belted & New Zealand \\
\hline $\begin{array}{l}\text { Total no. of blastocysts } \\
\text { Does with viable blastocysts (\%) } \\
\text { No. of blastocysts/doe* (range) } \\
\text { Degenerate blastocysts (\%) } \\
\text { No. of blastocysts as a percentage } \\
\text { of the no. of corpora lutea } \\
\text { No. of corpora lutea/doe* (range) }\end{array}$ & $\begin{array}{c}168 \\
73 \\
7 \cdot 0(1 \text { to } 9) \\
24 \\
97 \\
7 \cdot 2(4 \text { to } 11)\end{array}$ & $\begin{array}{c}230 \\
87 \\
11.5(4 \text { to } 15) \\
9 \\
99 \\
11.7(9 \text { to } 15)\end{array}$ \\
\hline
\end{tabular}

* Does with no blastocysts are excluded.

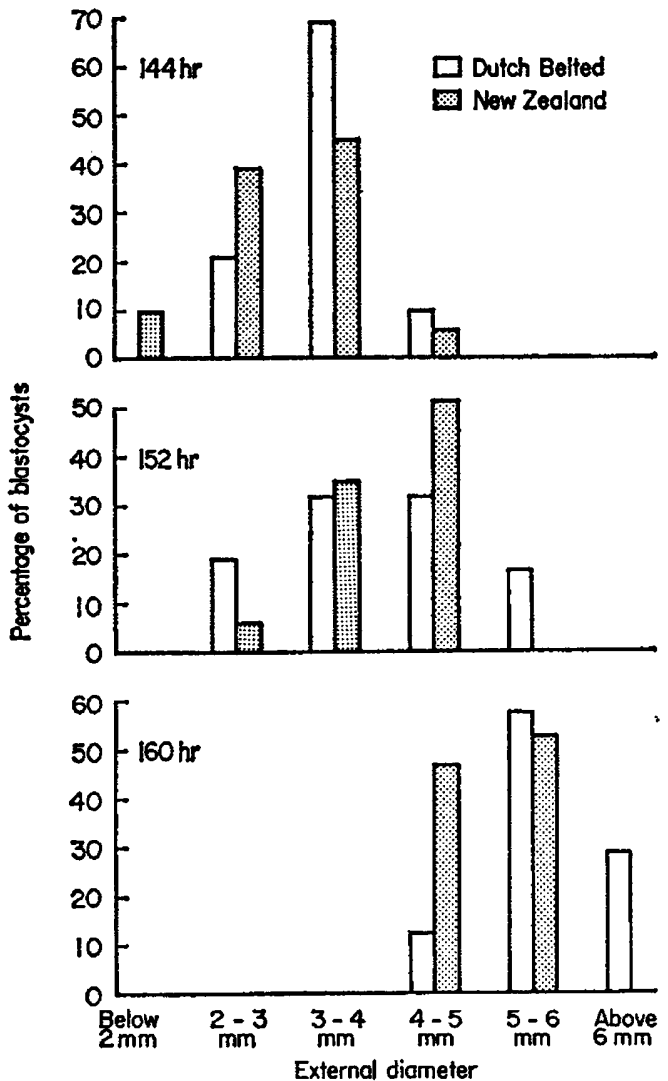

TexT-FIG. 1. Variation in size of blastocysts recovered from Dutch-Belted and New Zealand rabbits 144 to $160 \mathrm{hr}$ p.c.

high percentage of under- and over-sized blastocysts in the New Zealand breed at $144 \mathrm{hr}$ p.c. and in the Dutch-Belted breed at $152 \mathrm{hr}$ p.c. (Text-fig. 1). The individual variation seemed to decline in both breeds at $160 \mathrm{hr}$ p.c. Differences 


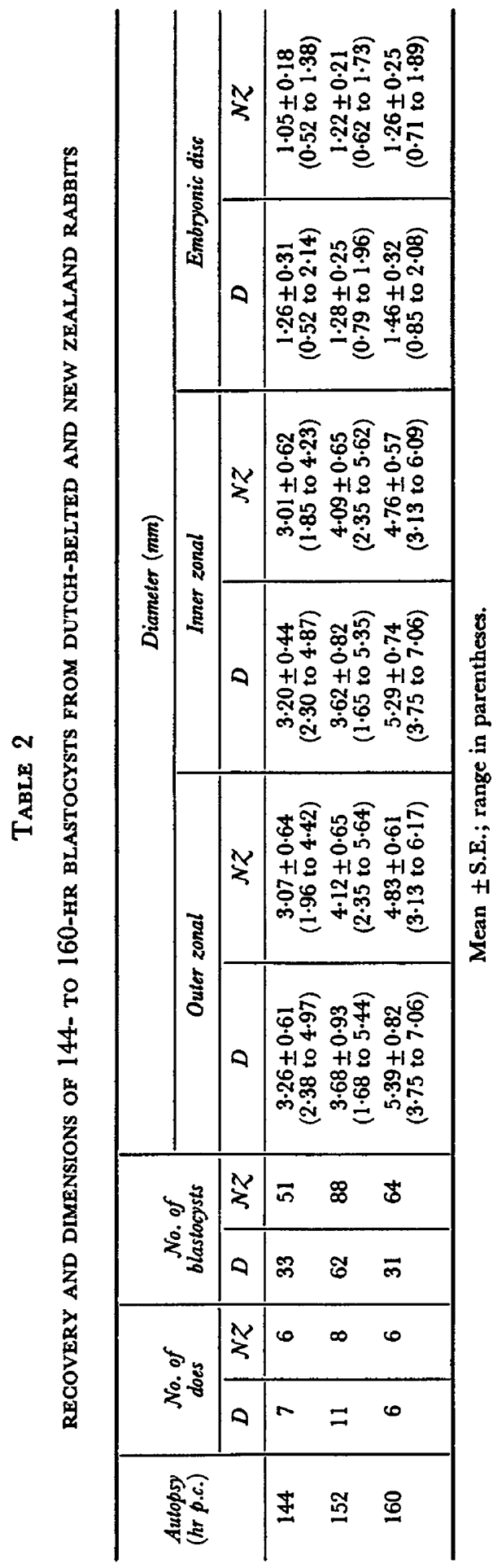


in blastocyst size within the same uterine horn may be due to differences in the time when eggs are ovulated or fertilized, genetic factors or maternal effects. However, there is no significant difference in the blastocyst size of New Zealand and Chinchilla breeds (Hafez \& Rajakoski, 1964). Breed differences in the pre-natal size of rabbits seem to be more pronounced after implantation of the blastocyst.

The investigation was supported in part by U.S. Public Health Service Research grant HD-00585 from the National Institute of Child Health and Human Development.

\section{REFERENCES}

Beatty, R. A. (1958) Variation in the number of corpora lutea and in the number and size of 6 day blastocysts in rabbits subjected to superovulation treatment. F. Endocr. 17, 248.

CAstle, W. E. \& Gregory, P. W. (1929) The embryological basis of size inheritance in the rabbit. 7. Morph. 48, 81 .

Hafez, E. S. E. \& IshibAsHI, I. (1965) Effect of lactation and age of first breeding on size and survival of rabbit blastocysts. Int. $\mathcal{F}$. Fert. $10,47$.

HAfEz, E. S. E. \& RAJAKoski, E. (1964) Growth and survival of blastocysts in the domestic rabbit. F. Reprod. Fert. 7, 229. 